\title{
CARACTERIZACIÓN FERMENTATIVA Y NUTRICIONAL DE MEZCLAS ENSILADAS DE CORONA DE PIÑA CON GUINEO CUADRADO Musa (ABB) I. Parámetros fermentativos, análisis bromatológico y digestibilidad in vitro.
}

Gerson J. Lazo-Salas ${ }^{1}$, Augusto Rojas-Bourrillon ${ }^{2}$, Carlos M. Campos-Granados ${ }^{2}$, Carlos ZumbadoRamírez ${ }^{3}$, Michael López-Herrera ${ }^{2}$

\section{RESUMEN}

Esta investigación se realizó con el objetivo de determinar y analizar las características bromatológicas, fermentativas y potencial digestivo de ensilados de corona de piña con cuatro niveles de sustitución de guineo cuadrado Musa (ABB). Se utilizó un diseño irrestricto al azar con 4 tratamientos de mezclas en base fresca de corona de piña y guineo cuadrado inmaduro en relación 100:0 85:15, 70:30 y 55:45 con cinco repeticiones por tratamiento. A las mezclas se les adicionó un $1 \%$ de melaza y se fermentaron durante 70días. No se utilizó inóculo bacterial. Se utilizaron silo bolsas de $50 \mathrm{~kg}$ para el almacenamiento del material. Se cuantificó un aumento significativo $(p<0,05)$ en los contenidos de materia seca, digestibilidad in vitro de la materia seca, pectinas, carbohidratos no fibrosos en los ensilajes conforme se aumentó el nivel de sustitución de guineo cuadrado en la mezcla. Los contenidos de proteína cruda, cenizas y ácido acético, ácido propiónico, disminuyeron significativamente $(p<0,05)$ conforme se aumentó el nivel de sustitución de guineo cuadrado. No se encontraron diferencias significativas $(p<0,05)$ para los contenidos de nitrógeno amoniacal, ácido butírico, ácido láctico, extracto etéreo ni para el pH entre las cuatro mezclas evaluadas. Se concluye que mezclas de la corona de piña (70\%) con el guineo cuadrado (30\%) Musa (ABB) se preservan mediante el proceso del ensilaje y representa una opción el mejoramiento nutricional de la corona en la alimentación de rumiantes. Se recomienda aumentar los niveles de inclusión de melaza para promover una mejor fermentación del ensilaje.

Palabras clave: ensilaje, calidad nutricional, alimentación animal, subproductos, rumiantes.

\footnotetext{
${ }^{1}$ Ministerio de Agricultura y Ganadería. Agencia de Servicios Agropecuarios Aguas Claras. Alajuela, Costa Rica

${ }^{2}$ Universidad de Costa Rica, Escuela de Zootecnia y Centro de Investigaciones en Nutrición Animal. Autores para correspondencia: augusto.rojas@ucr.ac.cr, carlosmario.campos@ucr.ac.cr, michael.lopez@ucr.ac.cr

${ }^{3}$ Ministerio de Agricultura y Ganadería. Agencia de Servicios Agropecuarios Upala. Alajuela, Costa Rica. zumbado.c@mag.co.cr

Recibido: 02 mayo 2018 Aceptado: 20 junio 2018
} 


\section{ABSTRACT}

\section{Fermentative and nutritional characterization of ensiled mixtures of pineapple} crown and guineo cuadrado banana Musa (ABB) I. Fermentative parameters, bromatologic analysis and in vitro digestibility. An study was conducted to analyzed the effect of ensiled mixtures of chopped pineapple crowns and guineo cuadrado banana fruit Musa $(A B B)$ on silage fermentation parameters and nutritive value. $A$ random and unrestricted design was used with four treatment (mixtures) and 5 replicates per treatment. The materials were mixed wet basis on a ratios of 100:0; 78:15; 70:30, 55:45 pineapple crowns: guineo cuadrado Musa $(\mathrm{ABB})$ respectively. Molasses was added al $1 \%$ wet basis and fermentation period last 70 days. The mixtures were stored in $50 \mathrm{~kg}$ silos bags. The addition of guineo cuadrado Musa $(A B B)$ increased $(p<0,05)$ the dry matter, non fibrous carbohydrates, pectin content and in vitro dry matter digestibility of the silages. Crude protein, ash, acetic acid and propionic acid content decreased $(p<0,05)$ by the addition of guinea cuadrado in the mixture. No statistical differences were detected on ether extract, amoniacal nitrogen, isobutiric acid, butyric acid, lactic acid content and $\mathrm{pH}$ values among treatments. It is conclude that mixtures of pineapple crowns $(70 \%)$ and guinea cuadrado banana $(30 \%)$ Musa (ABB) can be stored by ensiling process and causes a nutritive improvement of pineapple crown as feedstuffs for ruminants. It is recommended to increase the amount of molasses to promote a better silage fermentation.

Key words: silage, nutritive value, animal feeding, byproducts, ruminants. 


\section{INTRODUCCIÓN}

Según datos de la FAO (2016), más de un billón de personas dependen del sector ganadero. Esto evidencia la importancia de estudiar los factores más limitantes en la producción ganadera; como la alimentación, que representa el rubro más alto en los costos de producción y una preocupación constante en cuanto a disponibilidad de insumos durante el año.

Las pasturas son un componente importante en la alimentación de rumiantes y en el trópico estas están dominadas por gramíneas (Birbe et al., 2006). La digestibilidad y el contenido de energía son bajos en las pasturas tropicales y aunado a la existencia de periodos de escasez de agua, generan una baja productividad en los animales (Sampaio et al., 2009).

Por lo tanto, se deben diseñar estrategias de alimentación menos vulnerables a las condiciones ambientales (como largos periodos de sequía o de lluvia), que aporten la cantidad y calidad suficiente de nutrimentos al mínimo costo (Tobía y Vargas, 2000). La técnica del ensilaje asegura la disponibilidad del recurso alimenticio durante todo el año en sistemas de producción de rumiantes, además al ser aplicable a diversos materiales vegetativos, su utilidad y su fácil implementación por parte de los productores surge como una opción viable (Titterton y Bareeba, 2001).

En el componente agrícola, la piña es la tercera fruta tropical de importancia económica en el mundo, después del banano y el melón (Adegbite et al., 2014), siendo Filipinas, Brasil, Costa Rica, Tailandia y China los principales países productores, representando el $55 \%$ de la producción mundial. Vinculado al crecimiento de producción de piña a nivel nacional, se ha dado un incremento en la cantidad de subproductos que se obtienen de su cultivo e industrialización, como la planta entera, las coronas, los tallos, las cáscaras, los rastrojos (plantas sin raíces), la pulpa y el corazón (López-Herrera et al., 2014).

Diversas investigaciones han sido realizadas con subproductos del cultivo de la piña, las cuales demuestran que poseen una composición nutricional similar a forrajes empleados en sistemas ganaderos y que pueden ser conservados por medio de la técnica del ensilaje para su posterior utilización (Gutiérrez et al., 2003; López-Herrera et al., 2009; Rodríguez et al., 2014). Además, esta técnica de conservación representa una solución al 
problema ambiental que genera el manejo de estos materiales a nivel de las fincas productoras y plantas procesadoras. Adicionalmente, otro cultivo son las plantas del género Musa, estas en Costa Rica tienen una amplia distribución, no presentan estacionalidad y pueden ser ofrecidas las plantas completas (tallo, hojas y fruto), en cualquier momento del año para la alimentación de los animales (Izquierdo 2009).Experiencias previas descritas por López Herrera et al. (2017), han demostrado el potencial productivo animal de mezclas ensiladas de plátano Pelipita Musa (ABB) con de pasto Camerún (Cenchrus purpureum) lo que permiten considerar estas mezclas como opción tropical para la alimentación de bovinos.

El objetivo de la presente investigación, es cuantificar las características fermentativas y el contenido nutricional de ensilajes de mezclas en base fresca de corona de piña (Ananas comosus) con sustitución por guineo cuadrado Musa (ABB), como fuente forrajera para la alimentación de rumiantes.

\section{MATERIALES Y MÉTODOS}

\section{Ubicación y material utilizado}

El experimento se realizó en Finca Zapote propiedad del señor Alexander Arguello Rodríguez, ubicada en El Jácamo del cantón de Upala, provincia de Alajuela, con una temperatura anual promedio de $26^{\circ} \mathrm{C}$ y una precipitación total media de $2400 \mathrm{~mm} / \mathrm{año}$ (Villalobos et al., 2013). Para la elaboración de lo ensilajes se utilizó coronas de piña picadas a un tamaño de partícula de $5-10 \mathrm{~cm}$ y frutos de guineo cuadrado Musa (ABB) que fueron desprendidos de forma manual del pinzote y picados con cáscara a un tamaño de 2-4 cm en una picadora eléctrica para pasto.

\section{Preparación de los ensilajes}

Utilizando un diseño irrestricto al azar se prepararon cuatro tratamientos de corona de piña y fruto de guineo cuadrado en proporciones 100:0, 85:15,70:30, 55:45 respectivamente en base fresca. Los materiales se mezclaron manualmente y se depositaron en bolsas de polietileno (silobolsas) con un grosor de 0,063 mm y una capacidad de $50 \mathrm{~kg}$ para un total de 5 silobolsas por tratamiento. Se adicionó melaza al 
$1 \%$ en base fresca a todas las mezclas. No se adicionó inóculo bacterial. El material fue compactado mediante pisoteo y al finalizar el llenado se incluyó un sello de sal en el área de cerrado de la bolsa. Los ensilajes se alojaron protegidas del sol, lluvia, animales durante el período de fermentación de 70 días. El análisis bromatológico de los ingredientes usados se denota en el Cuadro 1.

Cuadro 1.Composición bromatológica de la corona de piña, el guineo cuadrado utilizados

\begin{tabular}{lcc}
\hline & Corona de piña & Guineo cuadrado \\
\hline MS (\%) & 9,10 & 20,80 \\
DIVMS (\%) & 80,60 & 93,60 \\
PC (\%) & 12,09 & 4,38 \\
EE (\%) & 2,86 & 2,07 \\
Cenizas (\%) & 8,79 & 4,57 \\
FDN (\%) & 57,50 & 14,50 \\
FDA (\%) & 32,50 & 9,10 \\
NIDA (\%) & 0,16 & 0,29 \\
NIDN (\%) & 0,51 & 0,35 \\
Lignina (\%) & 2,50 & 3,90 \\
\hline MS=materia seca; DIVMS=digestibilidad in vitro de la materia seca; PC=proteína \\
cruda; EE= extracto etéreo; FDN=fibra en detergente neutro; FDA=fibra en \\
detergente ácido; NIDA= nitrógeno indigestible en detergente ácido; NIDN= \\
nitrógeno indigestible en detergente neutro.
\end{tabular}

\section{Análisis de laboratorio}

Una vez abiertos los silos, estos se muestrearon manualmente de la sección media de la bolsa e inmediatamente En la apertura de los silos se determinó las características organolépticas de color, olor, textura y grado de humedad utilizando los indicadores planteados por Betancourt et al. (2005). Se determino el contenido de materia seca (MS), proteína cruda (PC), extracto etéreo (EE) y cenizas (AOAC 1998). El contenido de 
pectinas (Loyola et al., 2013); carbohidratos no fibrosos (CNF) Van Soest et al., (1991) y la digestibilidad in vitro de la materia seca (DIVMS) según Van Soest y Robertson (1985).

El contenido de ácidos grasos volátiles (AGV) (ácido acético, ácido propiónico, ácido butírico, y ácido láctico), fueron determinados según la metodología descrita por Ewen (2011), mediante cromatografía líquida de alto desempeño (HPLC), utilizando una columna Hi-Plex $\mathrm{H}$, de la marca Agilent. Por otra parte, el nitrógeno amoniacal se determinó mediante la metodología empleada por Tobía et al., (2004). La determinación del pH según la metodología de la AOAC (2012), haciendo uso de un potenciómetro con electrodo de hidrógeno.

\section{Análisis de la información}

El análisis de la información se realizó a través de un análisis de varianza (ANOVA) utilizando el software estadístico InfoStat (Di Rienzo et al., 2016). La comparación entre medias de tratamientos, en caso que dicho efecto resulte significativo $(p<0,05)$, se realizó a través de la prueba de Waller-Duncan. Para determinar si se presentaron diferencias significativas en las pruebas organolépticas se hizo uso de la prueba de Kruskal-Wallis con un $95 \%$ de confianza.

\section{RESULTADOS Y DISCUSIÓN}

\section{Características organolépticas de los ensilados}

Al realizar el análisis de las pruebas organolépticas, se determinó que no existían diferencias significativas entre tratamientos para el caso del olor, color y textura 
Color: En esta variable se generaron diferencias $(p<0,05)$ debidas a la sustitución pro guineo cuadrado. Los ensilados presentaron una coloración que iba del amarillo/verde claro hacia el verde pardo, relacionado al incremento en el nivel de sustitución de guineo cuadrado. Según lo señalado por Betancourt et al., (2005) podría interpretarse que al incrementar el nivel de guineo cuadrado se disminuye la calidad del ensilado, no obstante, existe un efecto llamado "pardeamiento enzimático" en el que una alteración química aparece en productos vegetales que han sido troceados o que han sufrido contusiones, y no siempre la formación de estos pigmentos se ha de considerar como un fenómeno químico indeseable; este efecto tiene como sustrato a los compuestos fenólicos y un ejemplo de estos son los taninos, los cuales están presentes en los frutos verdes de las musáceas (Bello, 2000).

Olor: Se logró percibir en la mayoría de los tratamientos, olores acéticos en combinación con olores dulces, estos últimos son propios de los procesos donde se formó ácido láctico, no obstante, pueden ser obtenidos cuando se da fermentación alcohólica gracias al metabolismo de levaduras (Driehuis y Van Wikselaar, 2000). Esto indica que los ensilados son de buena calidad, sin embargo, en una repetición dañada se lograba percibir un fuerte olor a putrefacción, esto es propio de materiales de mala calidad, donde se ha generado ácido butírico debido a mayor actividad de bacterias clostridiales (Betancourt et al., 2005).

Textura: La disposición del material y si se forman o no aglomeraciones en lo ensilados resultaron significativas $(p<0,05)$ sólo en los tratamientos con $45 \%$ de sustitución con guineo cuadrado. Los tratamientos conservaron la textura original de la corona de piña y del guineo cuadrado, estos no se degradaron, no eran viscosos, ni se destruían al contacto, además se segregaban con facilidad, por lo tanto, se pueden considerar en cuanto a su textura como ensilajes de buena calidad (Betancourt et al., 2005). Por el contrario, en la repetición dañada se formaba una masa jabonosa y pegajosa.

\section{Características fermentativas de las mezclas ensiladas}

En el Cuadro 2 se aprecia las características fermentativas y contenido de materia seca de los ensilajes. Los contenidos de materia seca aumentan al incrementar el aporte de fruto de guineo en la mezcla asociado al mayor contenido de este nutriente en el fruto. 
Cuadro2. Características fermentativas de las mezclas ensiladas de corona de piña con niveles crecientes de guineo cuadrado.

\section{Tratamiento}

\begin{tabular}{cccc}
$\begin{array}{c}\text { Corona:Fruto } \\
\text { Guineo }\end{array}$ & $\begin{array}{c}\text { MS } \\
(\%)\end{array}$ & $\begin{array}{c}\text { Nitrógeno Amoniacal } \\
\text { (\% del nitrógeno total) }\end{array}$ & $\begin{array}{c}\mathbf{p H} \text { (unidades de } \\
\mathbf{p H})\end{array}$ \\
\hline $\mathbf{1 0 0 : 0}$ & $12,80^{\mathrm{a}}$ & 9,22 & 4,65 \\
$\mathbf{8 5 : 1 5}$ & $14,00^{\mathrm{a}}$ & 9,32 & 4,66 \\
$\mathbf{7 0 : 3 0}$ & $16,80^{\mathrm{b}}$ & 8,03 & 4,55 \\
$\mathbf{5 5 : 4 5}$ & $19,50^{\mathrm{c}}$ & 5,75 & 4,66 \\
\hline
\end{tabular}

Medias con letras diferentes son significativamente diferentes según la prueba de Duncan $(p<0,05)$.

Debido a su contenido de humedad los ensilajes elaborado pueden ser considerados altos en humedad debido a que presentan contenidos de MS inferiores a $25 \%$ (Boschini y Elizondo, 2003) y similares a resultados obtenidos con ensilados de desechos de piña con pollinaza de 10,27\% a 18,91\% de MS (Gutiérrez et al., 2003), y de rastrojos de piña con pulpa de cítricos deshidratada de $14 \%$ a $22 \%$ (López-Herrera et al., 2009).

Un alto contenido de MS favorece la estabilización, y esto a su vez reduce las pérdidas de nutrimentos por efluentes, además existe una correlación positiva entre este parámetro y el consumo del animal (Rojas-Bourrillon et al., 1998), por lo que se considera conveniente hacer uso de materiales secantes en los ensilados, tales como la semolina, la pollinaza o la pulpa de cítricos deshidratada.

\section{Nitrógeno amoniacal como porcentaje del nitrógeno total $\left(\mathrm{NH}_{3} / \mathrm{NT}\right)$}

Ojeda et al., (1991) han establecido que ensilados de excelente calidad deben tener como valor crítico menos del $7 \%$ de $\mathrm{NH}_{3} / \mathrm{NT}$, asimismo, Moreno (1977) indica que concentraciones menores al $11 \%$ de $\mathrm{NH}_{3} / \mathrm{NT}$ se califican como ensilados buenos, mientras que ensilados de mala calidad se relacionan con valores superiores al $15 \%$ de $\mathrm{NH}_{3} / \mathrm{NT}$. Por lo tanto, bajo este indicador, ninguna de las mezclas ensiladas es de mala calidad y se considera el tratamiento con $45 \%$ de inclusión de guineo como un ensilado de excelente calidad mientras que los restantes ensilajes clasifican de buena calidad 
(Cuadro 2). Estos valores indican que los procesos proteolíticos, la desaminación de las proteínas o la conversión de otros constituyentes nitrogenados a amoniaco, no fueron de importancia.

Los resultados obtenidos son superiores a los encontrados en ensilados de rastrojos de piña con pulpa de cítricos deshidratada (2,84\% a 3,99\% (López-Herrera et al., 2009).Sin embargo, al compararlos con ensilados de Leucaena leucocephala (7\%) (Betancourt 2002), y ensilados de maíz (6,94\%) (Berndt, 2002) son similares. Por el contrario, tienen valores inferiores a los hallados en ensilados de trébol rojo (Trifolium sp.) $(14,4 \%)$, ryegrass $(10,0 \%)$ (McDonald, 1981), y de desechos de piña con pollinaza $(13,23 \%)$ (Gutiérrez et al., 2003).

\section{Valor de pH del ensilado}

Al contrastar los datos obtenidos con los reportados en ensilados de desechos de piña con pollinaza $(3,29)$ (Gutiérrez et al., 2003), ensilados de maíz $(3,89)$ (Giger-Riverdin et al., 2002) y ensilados de ryegrass $(3,90)$ (McDonald, 1981), se hace notable como los valores de $\mathrm{pH}$ conseguidos en este experimento son más altos (Cuadro 2). Sin embargo, son similares a lo encontrado en ensilados de Brachiaria brizantha con urea y minelaza $(4,5-5,8)$ (Pietrosemoli et al., 1997), ensilados de leguminosas con guineo cuadrado $(4,3$ - 4,8) (Montero, 2016) y ensilados de pasto Camerún con plátano Pelipita $(3,7-4,8)$ (López-Herrera et al., 2017).

Según lo propuesto por Moore y Peterson (1995), un ensilado alto en humedad debe poseer un $\mathrm{pH}$ entre 4,00 y 4,20 para ser calificado de buena calidad. Por lo tanto, los ensilados de este experimento bajo este indicador no son de buena calidad. Sin embargo, bajos niveles de $\mathrm{pH}$ se relacionan con detrimentos del consumo voluntario de materia seca (Soderlund, 1995), por lo que estos ensilados podrían presentar mejores consumos respecto a ensilados con $\mathrm{pH}$ más bajo.

La adición de fuentes de carbohidratos solubles es determinante para lograr la disminución del pH (López-Herrera et al., 2009), y es posible que los almidones provenientes del guineo cuadrado no participan activamente en el proceso de fermentación comportamiento similar a lo observado por López-Herrera et al., (2017) conmezclas ensiladas de plátano Pelipita Musa (ABB) con de pasto Camerun ( Cenchrus purpureum por lo que se concluye de la presente investigación sobre la necesidad de 
adicionar una mayor cantidad de carbohidratos solubles para asegurar una adecuada fermentación. En la presente investigación se adicionó 1\% de melaza lo que demostró no ser suficiente para reducir el $\mathrm{pH}$ a valores de 4,0 considerado aceptable para este tipo de ensilajes (Moore y Petersen, 1995).

\section{Ácidos Orgánicos}

En el Cuadro 3 se detalla sobre el contenido de ácidos orgánicos de cada uno de los tratamientos.

Cuadro 3. Contenido de ácidos orgánicos (como \% MS) en las mezclas ensiladas de corona de piña con niveles crecientes de guineo cuadrado.

\begin{tabular}{ccccc}
\hline $\begin{array}{c}\text { Tratamiento } \\
\text { Corona:Fruto Guineo }\end{array}$ & HAOc & HPOc & HBOc & HLOc \\
\hline $\mathbf{1 0 0 : 0}$ & $3,06^{\mathrm{a}}$ & $1,63^{\mathrm{a}}$ & 1,35 & 0,16 \\
$\mathbf{8 5 : 1 5}$ & $2,60^{\mathrm{b}}$ & $1,39^{\mathrm{ab}}$ & 1,38 & 0,14 \\
$\mathbf{7 0 : 3 0}$ & $1,91^{\mathrm{c}}$ & $1,17^{\mathrm{b}}$ & 1,44 & 0,11 \\
$\mathbf{5 5 : 4 5}$ & $1,31^{\mathrm{d}}$ & $0,79^{\mathrm{c}}$ & 1,27 & 0,19 \\
\hline
\end{tabular}

$\mathrm{HAOc}=$ Ácido acético. HPOc= Ácido propiónico.. HBOc= Ácido butírico.HLOc= Ácido láctico. Medias

con letras diferentes son significativamente diferentes según la prueba de Duncan $(p<0,05)$.

El INRA (1981), establece como valor crítico para el HPOc no más de 1\%, por lo que en este caso se considera que solo el tratamiento $45 \%$ de adición de guineo logra el valor óptimo de HPOc. Al comparar los resultados obtenidos para el HPOc con lo indicado en ensilados de leguminosas con diferentes fuentes de carbohidratos $(0,3 \%-0,6 \%)$ (LópezHerrera y Briceño-Arguedas, 2017), se hace notable que este experimento los valores fueron mayores.

Por otro parte, Tobía y Vargas, (2000) establecen que el HAOc debe ser menos de 1,8\% y no más de $6,0 \%$, debido a que el HAOc en el ensilado genera olor y sabor que influye de manera negativa sobre el consumo voluntario (Lara y Lara, 1977); por lo que en este 
experimento el contenido es considerado bueno para los tratamientos de 15 y $30 \%$ de adición y óptimo para el tratamiento con $45 \%$. Los valores de HAOc determinados son similares a lo indicado para ensilajes de leguminosas con guineo cuadrado $(0,9 \%-6,0 \%)$ (Montero, 2016), ensilados de desechos de piña con pollinaza (1,0\% - 2,9\%) (Gutiérrez et al., 2003), y ensilados de pejibaye (1,4\% - 1,6\%) (Rojas-Bourrillon et al., 1990).

El valor de HBOc debe ser menos de 0,1\% y no más de 2,0\% (Tobía y Vargas, 2000), por lo que se concluye que el valor de HBOc en este experimento es aceptable. Los resultados obtenidos para $\mathrm{HBOC}$ son similares a lo encontrado en ensilajes de leguminosas con guineo cuadrado $(0,6 \%$ - 4,5\%) (Montero, 2016), y en ensilados de desechos de piña con pollinaza $(0,0 \%-2,1 \%)$ (Gutiérrez et al., 2003), sin embargo, son mayores que lo encontrado en ensilados de pejibaye $(0,1 \%)$ (Rojas-Bourrillon et al., 1990).

Los contenidos de HLOc en este experimento son inferiores a los recomendados $(1,5 \%$ $3 \% \mathrm{MS}$ ); además, la formación de HLOc es necesario para llegar al pH ideal (De la RozaDelgado, 2005). Por tanto, se considera insuficiente para todos los tratamientos, lo que pudo haber ocasionado que no se alcanzara el pH idóneo. Al comparar los resultados obtenidos con los encontrados en ensilados de leguminosas con guineo cuadrado $(1,6 \%$ $3,9 \%$ ) (Montero, 2016), ensilados de desechos de piña con pollinaza $(1,3 \%-3,3 \%)$ (Gutiérrez et al., 2003), y ensilados de pejibaye (5,8\% - 6,4\%) (Rojas-Bourrillon et al., 1990), se hace notable como en este experimento los valores fueron menores. Es posible que en el presente experimento se den interacciones entre microorganismos asociado al grado de humedad, presencia de oxígeno causando variantes en el contenido de ácidos grasos así el ácido láctico puede ser degradado a ácido acético y otras sustancias en condiciones anaeróbicas en presencia de microorganismos heterofermentadores como el Lactobacillus buchneri (Sukhija y Palmquist, 1988). Esto puede ser beneficioso debido a que se ha relacionado la producción de $\mathrm{HAOc}$ con la estabilidad aeróbica, ya que inhibe el crecimiento de levaduras que son responsables del calentamiento al exponerse a oxígeno (Combs y Hoffma, 2012). En ensilajes con valores de $\mathrm{pH}$ superior a 4 y oxígeno disponible algunas de las bacterias que producen $\mathrm{HBOc}$ (Clostridium) degradan los azúcares y el HLOc a HBOc, lo cual eleva el pH e inicia el deterioro y la putrefacción, otras (proteolíticas) degradan proteínas a HBOc y amoníaco (De la Roza-Delgado, 2005). Dicha situación suele suceder cuando el forraje es demasiado húmedo y el pH no 
disminuye rápidamente, lo que genera pérdida de MS, descomposición y malos olores (Weinberg y Muck, 1996). Importante mencionar que en la presente investigación los ensilados presentaron buenas evaluaciones organolépticas.

\section{Contenido nutricional}

Los valores de proteína cruda, extracto etéreo, carbohidratos no fibrosos, cenizas y digestibilidad in vitro de las mezclas ensiladas se aprecian en el Cuadro 4.

Cuadro 4. Composición nutricional de mezclas ensiladas de corona de piña con niveles crecientes de guineo cuadrado.

\begin{tabular}{ccccccc}
\hline $\begin{array}{c}\text { Tratamiento } \\
\text { Corona:Fruto } \\
\text { Guineo }\end{array}$ & PC & EE & CNF & Pectinas & Cenizas & DIVMS \\
\cline { 2 - 7 } & \multicolumn{7}{c}{ \%MS } \\
\hline $\mathbf{1 0 0 : 0}$ & $8,27^{\mathrm{a}}$ & 3,35 & $17,76^{\mathrm{a}}$ & $3,90^{\mathrm{a}}$ & $21,14^{\mathrm{a}}$ & $79,50^{\mathrm{a}}$ \\
$\mathbf{8 5 : 1 5}$ & $7,16^{\mathrm{b}}$ & 3,80 & $29,89^{\mathrm{b}}$ & $11,90^{\mathrm{a}}$ & $16,73^{\mathrm{ab}}$ & $81,44^{\mathrm{ab}}$ \\
$\mathbf{7 0 : 3 0}$ & $6,03^{\mathrm{c}}$ & 3,65 & $45,32^{\mathrm{c}}$ & $21,10^{\mathrm{b}}$ & $14,49^{\mathrm{b}}$ & $84,94^{\mathrm{c}}$ \\
$\mathbf{5 5 : 4 5}$ & $5,68^{\mathrm{c}}$ & 3,89 & $50,61^{\mathrm{d}}$ & $22,43^{\mathrm{b}}$ & $13,62^{\mathrm{b}}$ & $83,90^{\mathrm{bc}}$ \\
\hline
\end{tabular}

Medias con letras diferentes son significativamente diferentes según la prueba de Duncan $(p<0,05)$.

\section{Proteína cruda (PC)}

Milford y Minson, (1965) indican que niveles inferiores al 7\% de PC en forrajes se asocia a bajos consumos, por tanto, de alimentar solo con los ensilados descritos en este experimento, se generaría un ambiente ruminal limitante para el desarrollo las bacterias, lo que disminuiría la tasa de digestión de la fibra y la tasa de pasaje ruminal. En consecuencia, se reduce el consumo de MS, la ganancia de peso y el rendimiento de los animales (Del Curto et al., 2000). El consumo podría regularse mediante suplementación proteica, o con adición de fuentes nitrogenadas en las mezclas, tales como: urea, harina de soya o pollinaza; lo cual podría ser material de experimentación para futuras investigaciones. Los valores de PC cuantificados son similares a los obtenidos con ensilados de rastrojos de piña con pulpa de cítricos deshidratada (8,24\% - 7,08\%) (LópezHerrera et al., 2009) y mayores a los descritos en ensilados de pejibaye $(4,95 \%-5,93 \%)$ 
(Rojas et al., 1990) y menores a ensilajes de desechos de piña con la adición de pollinaza (10,28-12,33\% ) obtenidos por Gutiérrez et al., ( 2003).

\section{Extracto etéreo (EE)}

Considerando el valor máximo en la materia seca total sugerido por Palmquist, (1986) para dietas de rumiantes de un $7 \%$ de extracto etéreo, se puede inferir de los resultados de la presente investigación poco riesgo tóxico sobre los microorganismos ruminales si se utiliza estas mezclas como única fuente alimenticia. Además se puede considerar que los contenidos de lípidos de las mezclas son despreciables de acuerdo a Weiss et al., (1992) quienes indican un $50 \%$ de digestión del extracto etéreo.

\section{Carbohidratos no fibrosos (CNF)}

El contenido de CNF aumentó conforme incrementó el contenido de guineo cuadrado, sin embargo, la ración total del ganado lechero debe contener entre 30 y $40 \%$ de carbohidratos no fibrosos (Chase y Sniffen, 1991). Aportes mayores de CNF deben de considerar la adición de fuentes sustitutas del almidón como fibras fermentables y pectinas. Se aprecia en el cuadro que los valores de CNF con los niveles de inclusión de 30 y $45 \%$ de guineo superan las recomendaciones. Sin embargo, debe considerar que estos valores incluyen los aportes de pectinas lo que permitiría su empleo sin riesgo para la salud ruminal con la ventaja de aportes importantes para la síntesis de proteína microbial y producción de ácidos grasos volátiles.

Los valores de CNF cuantificados son similares a los publicados en NRC 2001 de 28,9$39,8 \%$ para ensilajes de maíz con menos del $25 \%$ de MS, lo que permite apreciar el potencial de las mezclas de corona y guineo cuadrado. Así mismo, la presencia del guineo en la mezcla mejora este indicador nutricional como se aprecia al comparar los presentes resultados con la información disponible sobre desechos de la actividad piñera tales como en los ensilajes de rastrojo de piña $(8,72-21,22 \%)$ y desechos de la industrialización de la fruta (18,64-12,34\%) presentados por Rodriguez et al., (2014) y Gutiérrez et al., (2003) respectivamente.

\section{Pectinas}

Las pectinas son el carbohidrato complejo que se degrada de manera más rápida en el rumen, mientras que los almidones y la celulosa varían de acuerdo con la fuente. Sin 
embargo, aunque la pectina sea muy fermentable, no se incurre en el riesgo de reducir en demasía el pH ruminal, ya que está asociada a la estructura del ácido galacturónico que le confiere capacidad amortiguadora (Rojas-Bourrillon, 1995). Además, su fermentación a nivel ruminal tiende a generar como producto acetato, que al metabolizarse aumenta la producción de leche y el contenido de grasa láctea (Relling y Mattioli, 2003). Bajos esta consideración es posible aumentos en la producción de leche y el contenido de grasa láctea, en los animales que se alimenten con las mezclas con mayor contenido de guineo cuadrado debido al mayor contenido de pectinas en estas.

\section{Cenizas}

El nivel de cenizas disminuye conforme aumenta el nivel de sustitución de guineo cuadrado, asociado a que el guineo cuadrado posee un valor de cenizas más bajo que la corona de piña. Al contrastar los resultados obtenidos en esta investigación es notable como son mayores a los obtenidos en ensilados de rastrojos de piña con pollinaza (10\% 8,7\%) (López-Herrera et al., 2009), ensilados de rastrojos de piña con urea y minelaza $(8,48 \%$ - 13,55\%) (Rodríguez et al., 2014), ensilado de maíz (5,5\%) y ensilado de soya CIGRAS 06 (5,5\%) (Tobía et al., 2004) lo que podría asociarse a contaminaciones con suelos durante el manejo de la corona o en la elaboración de los ensilajes como lo propone Chaverra y Bernal, (2000) al cuantificar contenidos mayores a $12 \%$ vinculados a contaminación con suelo.

\section{Digestibilidad in vitro de la materia seca (DIVMS)}

Valores altos de DIVMS como los obtenidos en este experimento, se han asociado con la capacidad de los rumiantes para mantener niveles adecuados de producción, ya que es un indicativo de la capacidad de un alimento para aportar nutrientes a la flora ruminal (Preston y Leng, 1990). Offner et al., (2003), indican que el almidón presente en los CNF es más digerible que la FDN, aunado a esto, en este experimento conforme aumenta el contenido de guineo cuadrado aumenta los CNF y decrece la FDN(datos no publicado) por lo tanto, es de esperar un incremento en la DIVMS conforme incremente el contenido de guineo cuadrado. Por otra parte, el contenido de FDA y lignina se correlacionan negativamente con la DIVMS (Harris, 1993). En este experimento mientras incrementó el contenido de guineo cuadrado, disminuyó el valor de FDA (datos no publicado), esto explica en parte el incremento de la DIVMS al incluir el guineo en el silo con corona. No 
obstante, el incremento en el contenido de guineo cuadrado, aumentó el valor de lignina (datos no publicados), lo que explica la disminución de la DIVMS del tratamiento en los niveles de $45 \%$. Este comportamiento sobre la lignina es similar al informado por Herrera et al., (2017) al incluir plátano Pelipita en los ensilajes de Camerún. Asimismo, el guineo cuadrado contiene taninos que pueden inactivar los microorganismos y sus enzimas, por lo que la digestibilidad puede ser inhibida cuando se incrementa mucho el contenido de guineo en la ración (Ramírez-Orduña et al., 2002).

En general los resultados de DIVMS obtenidos permiten considerar que las mezclas de ensiladas de corona de piña y el guineo tienen gran potencial para satisfacer requerimientos nutricionales del rumiante. Estos valores de DIVMS son similares a los publicados en ensilados de pejibaye (83,71\% - 88,20\%) (Rojas-Bourrillon et al., 1990), rastrojos de piña $(74,9 \%$ - 85,12\%) (López-Herrera et al., 2009) y ensilados de desechos de piña (82,30\%) (Gutiérrez et al., 2003).

\section{CONSIDERACIONES FINALES}

A pesar de considerarse la corona de piña como un recurso alimenticio aceptable para la alimentación de rumiantes sea fresca o ensilada, se demuestra, que la adición de una fuente de almidones, en este caso mediante la musácea tropical guineo cuadrado Musa (ABB), permite aumentar su valor nutricional y potenciar la respuesta productiva de los animales en el trópico. La sustitución de corona por guineo genera valores de $\mathrm{pH}$ característico de ensilajes altos en humedad y cuando los niveles de sustitución de corona por guineo cuadrado son de un 30\% se mejora el proceso fermentativo al reducirse los contenidos de nitrógeno amoniacal, ácido butírico y se favorece el contenido nutricional al aumentar la digestibilidad in vitro de la materia seca. 


\section{LITERATURA CITADA}

Adegbite, O., O. Oni, y I. Adeoye. 2014. Competitiveness of pineapple production in Osun State, Nigeria. Journal of Economics and Sustainable Development. 5(2): 205-214.

AOAC (Association of Official Analytical Chemist). 1998. Official methods of analysis of AOAC International.16th ed, 4th rev. Gaithersburg, MD: AOAC International, USA.

AOAC (Association of Official Analytical Chemist). 2012. Official Method $945.10 \mathrm{pH}$ of Beer, Potentiometric Method. AOAC International, USA

Bello, J. 2000. Ciencia bromatológica: principios generales de los alimentos. Ediciones Díaz de Santos. Madrid, España. 596p.

Berndt, S. 2002. Composición nutricional y calidad de ensilajes de la zona sur. Tesis presentada para optar por el grado de licenciatura en Agronomía. Universidad Austral de Chile. Valdivia. Chile. 126 pp.

Betancourt, M., T. Clavero, y R. Razz. 2002. Características nutritivas del ensilaje de Leucaena leucocephalacon diferentes aditivos. Revista Científica. Vol. XII. Suplemento 2. 502-504 pp.

Betancourt, M., I. González, M. Martínez, y M. 2005. Evaluación de la calidad de los ensilajes. Revista Digital CENIAP HOY 8:1-5.

Birbe, B., P. Herrera, O. Colmenares, y N. Maertínez. 2006. El consumo como variable en el uso de bloques multinutricionales. X Seminario de Pastos y Forrajes. 43-61 pp.

Boschini, C., y J. Elizondo. 2003. Curso teórico y práctico de ensilaje de forrajes. Editorial de la Universidad de Costa Rica. 1er ed. San José, Costa Rica. 69p.

Castillo M., A. Rojas-Bourrillon, y R. WingChing-Jones. 2009. Valor nutricional del ensilaje de maíz cultivado en asocio con vigna (Vigna radiata). Agronomía Costarricense 33(1): 133-146.

Chase, L., y C. Sniffen. 1991. Balancing dairy rations to optimize rumen fermentation and milk production. In: Professional Dairy Management Seminar. Dubuque, USA. 5 p. 
Chaverra, G., y E. Bernal. 2000. Ensilaje en la alimentación de ganado vacuno. IICA. Tercer Mundo Editores. Bogotá, Colombia. 65 - 123. pp.

Combs, D., y P. Hoffman. 2012. Lactobacillus buchneri for Silage Aerobic Stability. Department of Dairy Science. University Wisconsin - Madison. Focus on Forage Vol 3: No. 14.

De La Roza-Delgado, B. 2005. El ensilado en zonas húmedas y sus indicadores de calidad. IV Jornadas de Alimentación Animal. Laboratorio de Mouriscade. Pontevedra, España. 20p.

Del Curto, T., B. Hess, J. Huston, y K. Olson. 2000. Optimum suplementation strategies for beef cattle consuming low-quality roughages in the western United States. Journal of Animal Science, 77: 1-16.

Di Rienzo, J., F. Casanoves, I. Balzarin, L. Gonzalez, M. Tablada, y C. Robledo. 2016. InfoStat. Grupo InfoStat, FCA, Universidad Nacional de Córdoba, Argentina. Disponible en http://www.infostat.com.ar

Driehuis, F., y Y. Van Wikselarr. 2000. The occurrence and prevention of etanol fermentation in high dry matter grass silage. Journal of the Science of Food and Agriculture 80(6): $711-718$.

Ewen, A. 2011. Organic acids in silage: Application note. Agilent Technologies. Estados Unidos. $3 p$.

FAO (Organización para la Agricultura y la Alimentación de las Naciones Unidas) 2016. Ganadería. Documento digital disponible en: http://www.fao.org/gender/genderhome/gender-programme/gender-livestock/es/. Consultado el 1 de abril de 2016.

Giger-Riverdin, S., C. Duvaux-Ponter, D. Sauvant, O. Martin, I. Nuñez do Prado, y R. Müller. 2002. Intrinsic buffering capacity of feedstuffs. Animal Feed Science and Technology. 96. 83-102 p.

Gutiérrez, F., A. Rojas-Bourrillon, H. Dormond, M. Poore, y R. WingChing-Jones. 2003. Características nutricionales y fermentativas de mezclas ensiladas de desechos de piña y avícolas. Agronomía Costarricense. 27(1): 79-89. 
Harris, B. 1993. Value of high-fiber alternative feedstuffs as extenders of roughage Sources. Disponible en http://www.inform.umd.edu

INRA (Institut National de la Recherche Agronomique).1981. Prévision de la valeur nutritive des aliments des ruminants. I.N.R.A Publications. Paris, France. 590p.

Izquierdo, H. 2009. Empleo del follaje de plantas de Musa ssp como alternativa para la alimentación animal. Temas de Ciencia y Tecnología, enero-abril:49-60.

Lara, Y., y P. Lara. 1977. Diferentes niveles de melaza y urea en el ensilaje de caña de azúcar (Saccharum officinarum). Tesis Magister Scientiae. Universidad de Costa Rica, Centro Agronómico Tropical de Investigación y Enseñanza. Turrialba, Costa Rica. 72 p.

López-Herrera, M., R. WingChing-Jones, y A. Rojas Bourrillon. 2009. Características fermentativas y nutricionales del ensilaje de rastrojo de piña (Ananas comosus). Agronomía Costarricense. Costa Rica. 33(1): 1-15.

López-Herrera, M., R. WingChing-Jones, y A. Rojas Bourrillon. 2014. Meta-análisis de los subproductos de piña para la alimentación animal. Agronomía Mesoamericana. Costa Rica. 25(2): 383-392.

López-Herrera, M., y E. Briceño-Arguedas. 2017. Efecto de la especie de leguminosa y la fuente de carbohidratos en la calidad física y química de mezclas para ensilaje. Nutrición Animal Tropical. Costa Rica. 11(1): 52-73

López-Herrera, M., A. Rojas-Bourrillon, y C. Zumbado. 2017. Características nutricionales y fermentativas de ensilados de pasto Camerún con plátano Pelipita. Agronomía Mesoamericana. Costa Rica. 28(3):629-642

Loyola., N., P. Núñez, y C. Acuña. 2013. Extracción y análisis de pectinas a partir de arándano (Vaccinium corymbosum L.) cv. O'Neall. Revista de la Facultad de Ciencias Agrarias. 45 (1). pp. 79-89.

McDonald, P. 1981. The Biochemistry of Silage. Jonh Wiley \& Sons. Ltd. New York. 226 pp. 
Milford, R., y D. Minson. 1965. Intake of tropical pasture species. In Proceedings 9th International Grassland Congress, Sao Paulo, Brasil. pp. 815-822

Montero, O. 2016. Evaluación de las propiedades fermentativas, nutricionales y el costo de elaboración de ensilajes de Poró (Erythrina poeppigiana) y Cratylia (Cratylia argentea) con niveles crecientes de inclusión de guineo cuadrado (Musa sp), para alimentación de rumiantes. Tesis de Licenciatura, Universidad de Costa Rica. Montes de Oca, Costa Rica. 60 pp.

Moore, K., y M. Peterson. 1995. Post-Harvest physiology and preservation of forages. Crop Science Society of America Inc. Special publication $N^{\circ} 22$. Wisconsin, USA. 91-107 p.

Moreno, A. 1977. Evaluación de ensilajes de pastos Panamá (Saccharum sinense), para la alimentación de vacas de doble propósito. Tesis M.Sc. Universidad de Costa Rica. Centro Agronómico Tropical de Investigación y Enseñanza. Turrialba. Costa Rica. 98 pp.

NRC (National Research Council). 2001. Nutrient Requirements of dairy cattle. 7 ed. National Academy Press, Washington DC., USA.

Offner, A., A. Bach, y D. Sauvant. 2003. Quantitative review of in situ starch degradation in the rumen. Animal Feed Sci. Technol. 106: 81 - 93.

Ojeda, F., O. Cáceres, y M. Eperance. 1991. Conservación de Forrajes. Editorial Pueblo y Educación. 80p.

Palmquist, D. 1986. Fat supplements for lactating cows. Ohio Dairy Day. The Ohio State University. Wooster, USA. $18 \mathrm{p}$.

Pietrosemoli, S., M. Ventura, y G. Gutiérrez. 1997. Adición de urea y melaza en la preparación de ensilaje de Brachiaria brizantha para bovinos en crecimiento. Arch. Latinoam. Prod. Anim. 5 ( supl 1): 205 - 207.

Preston, T., R. Leng. 1990. Ajustando los sistemas de producción pecuaria a los recursos disponibles: Aspectos básicos y aplicados del nuevo enfoque sobre la nutrición en el trópico. Círculo de Impresores Ltda. Cali, Colombia. 312 p. 
Ramírez-Orduña; R., R. Ramírez-Lozano, y F. López-Gutiérrez. 2002. Factores estructurales de la pared celular del forraje que afectan su digestibilidad. Ciencia UANL. México. 5(2): 189-189.

Ravi, I., M. Mustaffa. 2013. Starch and amylose variability in banana cultivars. Indian Journal of Plant Physiology 18(1): 83 - 87.

Relling, A., G. Mattioli. 2003. Fisiología Digestiva y Metabólica de los Rumiantes. Editorial EDULP. La Plata, Argentina. 74 pp

Rodríguez, S., M. López-Herrera, R. WingChing-Jones, y A. Rojas-Bourrillon. 2014. Adición de melaza deshidratada y urea en ensilados de rastrojos de piña. Agron. Mesoam. Costa Rica. 25(2):313-321.

Rojas-Bourrillon, A., A. Chávez, y C. Arroyo. 1990. Características nutricionales y fermentativas del ensilaje de fruto de pejibaye (Bactris gasipaes). Agronomía Costarricense. Costa Rica. 14(2). 157-160 pp.

Rojas-Bourrillon, A. 1995. Conceptos básicos en nutrición de rumiantes. Escuela de Zootecnia, Facultad de Agronomía. Universidad de Costa Rica. 175p.

Rojas-Bourrillon, A, H. Ugalde, y D. Aguirre. 1998. Efecto de la adición del fruto de pejibaye (Bactris gasipaes), sobre las características nutricionales del pasto gigante (Pennisetum purpureum). Agronomía Costarricense. Costa Rica. 22(2): 145-151.

Sampaio, C.B., E. Detmann, I. Lazzarini, M.A.D. Souza, M.F. Paulino, and S.D.C Valadares-Filho. 2009. Rumen dynamics of neutral detergent fiber in cattle fed lowquality tropical forage and supplemented with nitrogenous compounds. Revista Brasileira de Zootecnia 38:560-569.

Soderlund, S. 1995. Effect of moisture level and fermentation components of ensiled feedstuffs on voluntary dry matter intake. Okla. Agric. Exp. Sta. Misc. Publ. P942:264 
Sukhija, P., and Palmquist D. 1988. Rapid method for determination of total fatty acid content and composition of feedstuffs and feces. Journal of Agricultural and Food Chemistry. 36 (6), pp 1202-1206.

Titterton, M., y F. Bareeba. 2001. Ensilaje de gramíneas y leguminosas en los Trópicos, pp. 53-56. In: L. Mannetje (eds). Uso del ensilaje en el trópico privilegiando opciones para pequeños campesinos. Serie Estudios FAO. Producción y protección vegetal. 161. FAO, Roma. 189 pp.

Tobía, C., y E. Vargas. 2000. Inóculos bacterianos: Una alternativa para mejorar el proceso fermentativo en los ensilajes tropicales. Nutrición Animal Tropical. Costa Rica. 6(1): 129-143.

Tobía, C., A. Rojas, E. Villalobos, H. Soto, y L. Uribe. 2004. Sustitución parcial del alimento balanceado por ensilaje de soya y su efecto en la producción y calidad de la leche de vaca, en el trópico húmedo de Costa Rica. Agronomía Costarricense. Costa Rica. 28(2):27-35.

Van Soest, P., y J. Robertson 1985. Analysis of forages and fibrous feeds. Cornell University. Ithaca, New York. 165p.

Van Soest, P., J. Robertson, y B. Lewis. 1991. Methods for dietary fiber, neutral detergent fiber and non-starch polysacchrides in relation to animal nutrition. Dairy Sci. 74, 3583-3597.

Villalobos, R., E. Jiménez, K. Hernández, J. Córdoba, y P. Solano. 2013. Descripción del clima del Cantón de Upala. Ministerio de Ambiente y Energía. Instituto Meteorológico Nacional. Costa Rica. 18 p.

Weiss, W., H. Conrad, y N. St Pierre. 1992. A theoretically based model for predicting total digestible nutrient values of forage and concentrates. Animal Feed Sci. Tech. 39: $95-110$

Weinberg, Z., y R. Muck. 1996. New trends and opportunities in the development and use of inoculants for silage. FEMS Microbiological Views 19(1): 53-68. 